assuming a relaxed seated position for $10 \mathrm{~min}$, the subjects performed a mental arithmetic task for $60 \mathrm{~min}$ followed by relaxation for $30 \mathrm{~min}$, and then a rest for $10 \mathrm{~min}$. The mental arithmetic task is a method of adding numbers without using tools. Every subject performed both the control-load and aroma-load tests under the same protocol, while the ECG was measured. They smelled lavandula angustifolia during the aroma-load.

Result We analysed the power spectrum of high and low frequencies. The P1 (low frequen-cy)/P2 (high frequency) was defined as the ratio of P1 to P2. There was no change in the $\mathrm{P} 1 / \mathrm{P} 2$ of 2 out of 3 subjects by using the aroma. Subjects A and $\mathrm{B}$ could avoid mental stress by using the aroma during the mental arithmetic operation.

Discussion In an analysis of the power spectrum in the R-R interval times, the high and low frequencies in the physiological index of stress loading suggest that the aromas have an effect on the autonomic nervous system. As the strain on sympathetic nerve was relaxed, we conclude that the aroma affected the sympathetic nerves. Thus, we conclude that the aroma affected a sympathetic nerve, relaxing the strain on it.

\section{QUANTIFYING COMPETENCIES OF OCCUPATIONAL HEALTH NURSES IN JAPAN}

J Hatanaka*, K Kono, Y Kudo, Y Gotoh, K Nakagami. Occupational Health Nursing Research Centre, Yokkaichi Nursing and Medical Care University, Yokkaichi, Japan

\subsection{6/oemed-2018-ICOHabstracts. 1004}

Introduction Occupational health nurses can achieve high performance so that the competencies necessary for occupational health nursing practices are being acquired. The purpose of this study was to clarify how occupational health nurses are in possession of competencies required for occupational health nursing practices in Japan.

Methods An anonymous, self-administered questionnaire survey was conducted by mail. The questionnaires were distributed to 357 Japanese occupational health nurses and 211 were collected. (response rate, 56.3\%). 21 of 211 were excluded because of incomplete responses and 190 were analysed. We asked the rate at which they possessed 40 competencies developed by Kono, et al. All competencies were rated on a 7 point Likert scale $(1=$ Never, $7=$ Always). Data were collected between September 2016 and January 2017. We calculated descriptive statistics for all variables. As for the comparison of competencies' scores by years of experience as occupational health nurses, the Tukey HSD test was used. This study was approved by the ethical review board of Yokkaichi Nursing and Medical Care University.
Results The mean score of 8 competencies was more than 5.5 points. The mean score of 3 competencies was less than 4.5 points. All competencies' scores differed significantly by years of experience as occupational health nurses.

Discussion The competencies with high scores were common to nurses who had awareness of themselves as professionals, valuing human relations with clients, and supporting clients with respect. Therefore, we considered that these were competencies that were easy to acquire for occupational health nurses who learned nursing science. We also considered that some competencies might be low because nurses were not able to acquire them without opportunities for experience and activity.

\section{DEVELOPMENT OF A GROUP/ORGANIZATION-FOCUSED DIAGNOSTIC SHEET FOR OCCUPATIONAL HEALTH NURSING}

${ }^{1} \mathrm{M}$ Ito* ${ }^{2} \mathrm{~F}$ Akimoto, ${ }^{2} \mathrm{~K}$ Hara, ${ }^{2} \mathrm{~K}$ Masuzawa, ${ }^{3} \mathrm{M}$ Ito, ${ }^{3} \mathrm{H}$ Nakamur, ${ }^{3} \mathrm{M}$ Yanai, ${ }^{4} \mathrm{~K}$ Murakami, ${ }^{5} \mathrm{~A}$ Nagano, ${ }^{6} \mathrm{M}$ Seto, ${ }^{7} \mathrm{Y}$ Yamaguchi, ${ }^{8} \mathrm{R}$ Yoshida, ${ }^{9} \mathrm{~K}$ Kono, ${ }^{10} \mathrm{~A}$ Chiba, ${ }^{11} \mathrm{~N}$ Ochiai, ${ }^{12} \mathrm{M}$ Tachikawa, ${ }^{13} \mathrm{~K}$ Inomata. ${ }^{1}$ University of Tokyo Health Care, Tokyo, Japan; ${ }^{2}$ Nippon Telegraph and Telephone East Corporation, Tokyo, Japan; ${ }^{3}$ Occupational Health Nursing Systematisation Consideration Committee in JAOHN, Fukuoka, Japan; ${ }^{4}$ Tokyo Metro Co., Ltd., Tokyo, Japan; ${ }^{5}$ Suzuki Motor Corporation, Shizuoka, Japan; ${ }^{6}$ LOIN Corporation Health Support Office (Hirai), Tokyo, Japan; ${ }^{7}$ Sophia University, Tokyo, Japan; ${ }^{8}$ Epson Sales Japan Corp., Tokyo, Japan; ${ }^{9}$ Research Centre for Occupational Health Nursing, Yokkaichi Nursing and Medical Care University, Mie, Japan; ${ }^{10}$ Aomori University of Health and Welfare, Aomori, Japan; ${ }^{11}$ The University of Shimane, Shimane, Japan; ${ }^{12}$ Ube Frontier University, Yamaguchi. Japan; ${ }^{13}$ Teikyo Heisei University, Tokyo, Japan

\subsection{6/oemed-2018-ICOHabstracts. 1005}

Background Group/organization-focused quality nursing practices are expected of occupational health nurses, as the maintenance and promotion of the health of workers cannot be achieved without the wellbeing of the group/organisation in which they work.

Purpose In this research we developed a new sheet integrating diagnosis, outcome, and organisational support, in which the entire nursing process should be covered.

Methods Cases involving major workplace health issues were subject to discussion among members consisting of 3 nursing diagnosis researchers and 9 occupational health nursing specialists. During the discussion, Herdman Nursing Process, NANDA-I Nursing Diagnosis, and NIC-categorised Nursing Intervention were used for references.

Supervision by nursing diagnosis research specialists, advice from the special committee members of JAOHN, and opinions of nationwide working-group members were obtained.

Results The findings of the discussions, followed by qualitative analyses, were summarised for use in the sheet development.

\begin{tabular}{|c|c|c|c|c|}
\hline Nursing Diagnosis & & & & \\
\hline Diffinition & & & & \\
\hline \multirow{3}{*}{$\begin{array}{l}\text { Defining Characteristics } \\
\text { (Sign or symptom } \\
\text { (Objective or subjective cue)) }\end{array}$} & \multirow{3}{*}{$\begin{array}{c}\text { Related Factors } \\
\text { (cause,contrubuting factor) } \\
\text {./Risk Factor } \\
\text { (Determinant(increase risk) }\end{array}$} & Nursing Outcome & \multirow[b]{2}{*}{ Nursing support } & \multirow{3}{*}{$\begin{array}{l}\text { Opinion } \\
\text { Question }\end{array}$} \\
\hline & & \multirow{2}{*}{$\begin{array}{l}\downarrow \text { Number of corresponding } \\
\text { Defining Characteristics }\end{array}$} & & \\
\hline & & & $\downarrow$ Number of Nursing Outcome & \\
\hline & & & & \\
\hline & & & & \\
\hline & & & & \\
\hline
\end{tabular}

Abstract 562 Figure 1 Diagnostic sheet for occupational health nursing 
Diagnosis were made, definitions were clarified, and the nursing outcomes were identified based on the related factors, risk factors, and defining characteristics. After clarifying the challenges faced by the group/organisation, a diagnosis sheet was developed (figure 1).

Discussion The availability of this new sheet should encourage development of more systematised nursing diagnosis in occupational nursing, which is considered to be an urgent issue in Japan.

\section{THE STUDY OF COMPETENCY OF THE EMERGENCY FOR OCCUPATIONAL HEALTH NURSES}

${ }^{1} Y$ Matsuda*, ${ }^{2} \mathrm{M}$ Negishi, ${ }^{3} \mathrm{E}$ Furuhata, ${ }^{4} \mathrm{~K}$ Otani, ${ }^{5} \mathrm{E}$ Tomizawa, ${ }^{1,3} \mathrm{M}$ Arakida. 'International University of Health and Welfare Graduate School, Minato-ku Tokyo, Japan; ${ }^{2}$ Fujisawa Taxi Co., LTD., Fujisawa Kanagawa, Japan; ${ }^{3}$ International University of Health and Welfare, Odawara Kanagawa, Japan; ${ }^{4}$ Japanese Red Cross Toyota College of Nursing, Toyota Aichi, Japan; ${ }^{5}$ Sikoku University, Tokushima Tokushima, Japan

\subsection{6/oemed-2018-ICOHabstracts. 1006}

Introduction Emergencies care in occupational health care for organisations and groups and their individual departments and support for personal injuries and illnesses including life crises. However, the details of emergencies care in occupational health care are unclear. Therefore, the present study aimed to examine the competencies required of occupational health nurses (OHNs) in emergency care.

This study forms a part of efforts to construct a continuing education system for OHNs to improve their competencies in emergency care.

Methods A semi-guided interview was conducted with 10 OHNs. Referencing the data obtained from the research on continuing education for $\mathrm{OHN}$ s and the data obtained from the research on core curricula of nursing universities in Japan, these interview results were categorised base on their similarities and examined for their competencies in emergency care.

Results All participants in this study were women with 7-28 years of experience in occupational health nursing. The number of total employees at the workplace of each participant was assessed and it was established that for 2 of the participants there were $<300$ employees for each of their companies, for 1 of the participants there was 300-500 employees, for 3 other participants there were 500-1000 employees, for another 3 participants there were 1,000-3000 employees, and $\geq 10000$ for another one 1 of the participants. Items extracted from the results of the interviews included emergency treatment skills, motivation, preventive activities as well as team training and general employees education.

Conclusion The results suggested that to provide emergency care, OHNs must be able to identify life crises when they are occurring and provide emergency treatment, engage in preventive activities to prevent emergencies from occurring or aggravating, and exhibit ethical behaviour and professionalism in emergencies. Based on these details, we intend to further investigate the content of education and develop a continuing education program for OHNs.

\section{9 \\ A NATIONWIDE SURVEY ON THE CURRENT IMPLEMENTATION AND COMPETENCY OF OCCUPATIONAL HEALTH NURSES ON THE COLLABORATION WITH PUBLIC HEALTH SERVICES}

Yuko Mitsuhashi, Noriko Nishikido. Nursing School of Health Sciences, Tokai University

\subsection{6/oemed-2018-ICOHabstracts.1007}

Introduction We examined the current implementation and competency of occupational health nurses(OHNs) on the collaboration with public health services(PHS).

Methods A self-administered questionnaire was mailed to 2574 registered OHNs querying basic information, past PHS collaboration experience, direct PHS collaborative personnel, and competencies used in the collaboration. Our study was approved by the Ethics Committee, School of Health Sciences, Tokai University.

Results Of 815 recovered questionnaires (31.7\%), 806 were valid (31.3\%). Respondents' age group was most commonly 40-49 years (36.6\%). Mean total years of OHN experience was 14.7 years; 150 respondents $(18.6 \%)$ had public health nurse experience. Although 658 respondents (82.6\%) understood the necessity of the collaboration with PHS, only 285 (36.4\%) had PHS collaboration experience. Common collaborative partners were prefectural public health nurses(PHNs) (55.3\%) and PHNs who belong to cities and municipalities (52.5\%), suggesting OHNs collaborate with PHNs within the nursing field. The competency most commonly used by OHNs for general duties was including personal questions during interviews to establish a rapport so workers can discuss personal issues' (255 respondents, 90.4\%). The competency most commonly used in PHS collaboration was 'assisting workers in acquiring knowledge regarding problem-solving and utilising local resources' $(74.3 \%)$. Forty percent of respondents used a unique $\mathrm{OHN}$ competency, 'understanding that family members' health issues affect workers, and emphasising the need for support when relaying this to the personnel division'. Highly likely ( $\geq 80 \%$ validity) bases for PHS collaboration were 'open attitudes toward collaboration with professionals outside occupational health and nursing' and 'believing OHNs asking for outside help is normal when needed' in $77.4 \%$ and $73.5 \%$ of respondents, respectively.

Discussion Over $60 \%$ of OHNs did not collaborate with PHS despite understanding the necessity. Nurses who collaborated had unique competencies. Training for OHNs to acquire such competencies is necessary to ensure smooth PHS collaborations.

This study was funded by JSPS KAKENHI Grant Number 15 K11867 (Scientific Research C).

\section{OCCUPATIONAL HEALTH NURSING CHALLENGES IN DEVELOPING COUNTRIES: THE CASE OF ZIMBABWE}

F Moyo*. Midlands Occupational and Travel Health Centre, Gweru, Zimbabwe, Zimbabwe Occupational Health nurses, Harare, Zimbabwe

10.1136/oemed-2018-ICOHabstracts. 1008 